\title{
Environmental efficiency investigation of a gas turbine unit
}

\author{
Alexander Legkii, Natalya Karapuzova*, Alexei Kudashev, Vladimir Zlobin, and Oksana \\ Vlasova
}

Volgograd Technical University, 400074, Volgograd, Russia

\begin{abstract}
A method for purifying the gas-air mixture of a gas turbine unit and a waste-heat boiler is considered [1-3]. This work describes the principle of a gas-turbine plant and a waste-heat boiler operation using a catalytic afterburner, with the help of which a more complete process of carbon dioxide and nitrogenous compounds release occurs. Also, as a result of the exhaust gas-air mixture deeper cleaning process, there is a decrease in emissions within the maximum admissible concentrations (MAC), namely, by the amount of nitrogen and carbon oxides [4-7]. That allows to reduce the number of harmful substances, oxides of nitrogenous and carbon compounds, emitted into the environment. A scheme for cleaning a catalytic afterburner using rotary mesh devices, followed by disposal of carbon deposits and soot substances from the cleaning chamber is shown. This makes it possible to perform a stable ion exchange process, reducing the exhaust gases combustion products amount. It is proposed in this article to use mesh devices in the afterburner, treated with active substances by the method of ion implantation, as one of the most promising methods for modifying mesh surfaces. These processes occurring when the gas-air mixture passes through the afterburner, can reduce MAC emissions for various options for utilizing the discharge fuel mixture of a gas turbine unit (GTU) and heat supply to the waste heat boiler.
\end{abstract}

\section{Introduction}

Currently, the exhaust gases are sent to the waste heat boiler for the subsequent heat exchange process in the combustion chamber of the waste heat boiler to reduce the cost of fuel consumption and to reduce MAC gas turbine unit at power facilities where gas turbine units are installed. This is today one of the most effective systems for reducing the exhaust gas-air mixture combustion products emissions from a gas turbine into atmosphere.

\section{Purpose of the study}

This article is devoted to the study of reducing emissions of oxides of carbonaceous and nitrogenous compounds in the gas-air path of gas turbines and waste-heat boilers.

\footnotetext{
*Corresponding author: karapuzova_ny@mail.ru
} 


\section{Material and research methods}

Today, all gas turbine units operating on the principle of fuel mixture, natural gas and air combustion are one of the main sources of under burned fuel products emissions into the atmosphere, which include the main compounds: nitrogen and carbon oxides.

Gas turbine unitGTU-190 with a capacity of $190 \mathrm{MW}$ is designed for the production of electrical energy in basic and semi-peak modes. The unit can operate as a part of steam-gas blocks, as well as autonomously for district heating purposes. Fig. 1 shows a diagram of a gas turbine unit GTU-190 with an exhaust gas-air duct.

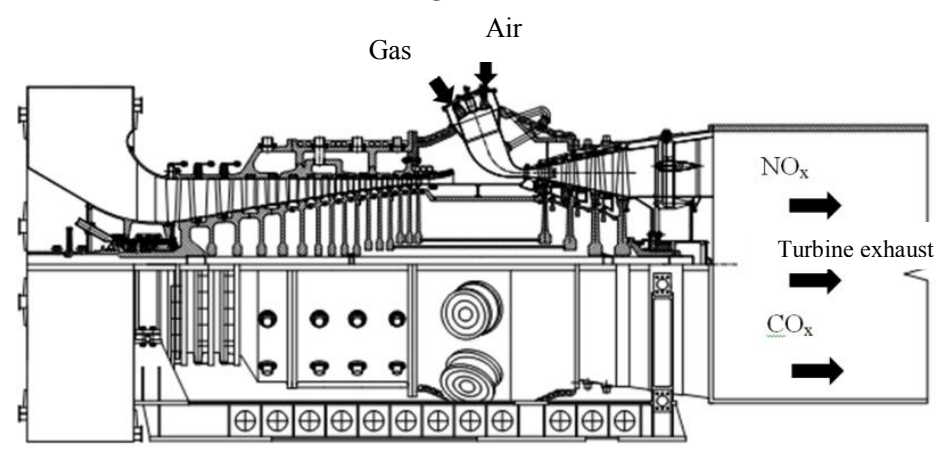

Fig. 1. Gas turbine unit GTU- 190diagram

Fuel combustion process in GTU-190 takes place inside the fuel injectors, where there is a partial mixing under pressure of a certain amount of air with natural gas. The working substance obtained in this way at the nozzles' outlet drives the rotor blades of the turbine, rotating the turbine rotor. Having passed through the high-pressure cylinder, the gas-air mixture along the guide vanes of the turbine changes its direction, entering the mediumpressure cylinder, where the gas-air mixture is refined, increasing the turbine efficiency with subsequent removal into the exhaust pipe.

Further, the discharge gas-air mixture with a significant amount of nitrogen and carbon compounds can be removed into the atmosphere, this scheme is valid for all gas turbine units, or sent to a waste heat boiler for the subsequent use of this mixture for the energy needs of the enterprise; such a cycle is called a steam-gas cycle. It will be considered in this paper.

To increase gas turbine unit efficiency, it is proposed to install a catalytic afterburner in the turbine exhaust pipe, in which the process of ion exchange of the exhaust gas-air mixture and catalytic meshes of the afterburner will take place. The proposed method of installing a catalytic afterburner makes it possible to increase the after burn substances amount production of carbon dioxide and nitrogen from the combustion products of the resulting gas-air mixture at the outlet of their burner of carbon and nitrogen oxides combustion and reduces the unburned hydrocarbons concentration [5]. The scheme of the catalytic afterburner installation in the exhaust pipe GTU-190 is shown in Fig. 2. 


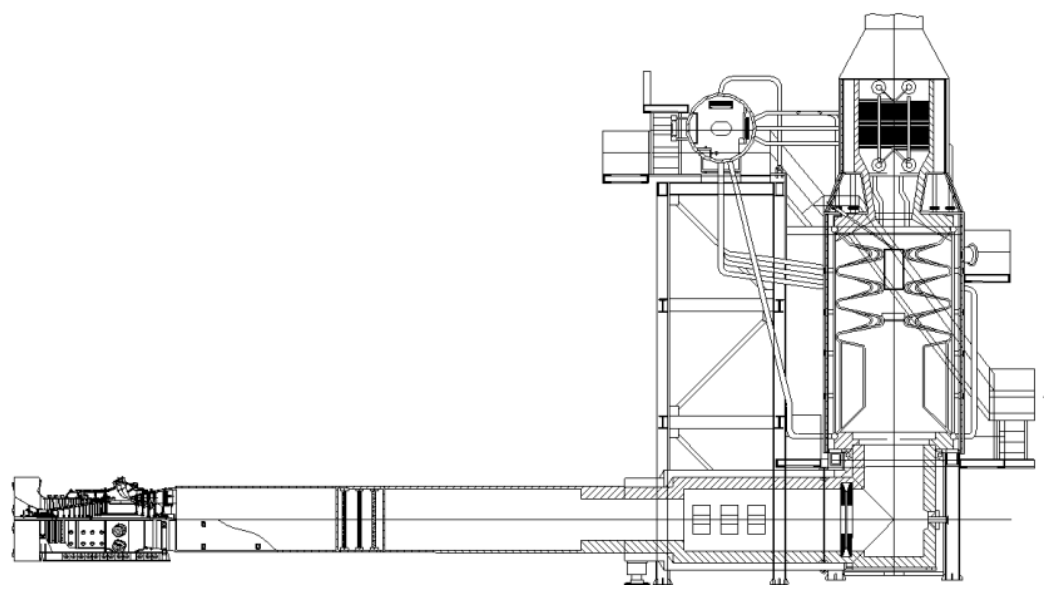

Fig. 2. Installation diagram of a catalytic converter in the exhaust pipe of GTU-190

When evaluating this connection diagram, it can be noted that with a constant flow rate of the exhaust gas-air mixture through the catalytic afterburner, the grating devices installed in it will lose their efficiency under the influence of high temperatures, as well as the formation of carbon and soot on their surfaces due to combustion products depositions.

So, to increase the catalytic after burner efficiency, it is proposed to use a system for cleaning alloyed gratings [7-9]. To create doped meshs, the method of ion doping of materials was used. This is a method of introducing impurity atoms into the surface layer of a substance by bombarding its surface with a high-energy ion beam (10-40 keV). Practically each element can be introduced into the near-surface region of any solid body placed in a vacuum chamber by bombardment with high-speed ions with this method [1014]. The scheme of cleaning the catalytic afterburner meshes is shown in Fig. 3.

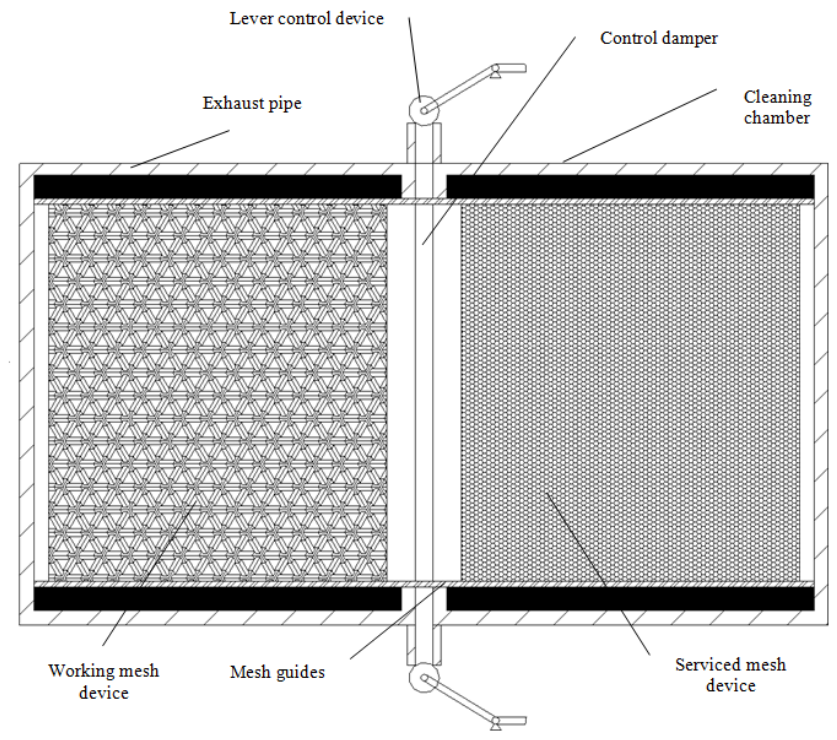

Fig. 3. Scheme of cleaning the meshes of the catalytic afterburner

The cleaning process of the catalytic converter mesh devices can be described as follows. If it is necessary to service the mesh devices, the control damper of the catalytic afterburner is opened, remotely using a lever control device for the damper, which connects 
the exhaust pipe, in which the catalytic converter is installed, with a cleaning chamber located on the outside of the exhaust pipe. Then the mesh devices are pushed into the cleaning chamber along the guides of the screens, where it is subsequently serviced or replaced with a new one. Then the control damper wall is closed the main heating equipment operation to be continued, as well as to speed up the cooling process of the mesh device. After performing the necessary operations, the mesh device is directed along its guides to the catalytic afterburner. Also, when the exhaust temperature and the temperature of the waste-heat boiler furnace part is changed, it is possible to quickly replace the mesh devices with the necessary intercellular space, to ensure the required temperature head of the gas turbine exhaust pipe and the waste-heat boiler.

\section{Conclusion}

The described study of the catalytic afterburner installation in the exhaust pipe of the GTU outgoing gas-air mixture, will make deeper cleaning of turbine exhaust gases from under burned products of the gas-air mixture possible. There is a decrease in the content of nitrogen and carbon oxides in the exhaust gas-air mixture, which will lead to a decrease in gas turbine unit MAC and will prevent the formation of the under burned products outgrowth inside the furnace section of the waste heat boiler, as well as will help to reduce harmful substances emissions into the atmosphere.

\section{References}

1. O.V. Komarov, V.L. Blinov, A.S. Shemyakinsky, Thermal and gas-dynamic calculations of gas turbine units (Publishing house of the Ural University, Yekaterinburg, 2018).

2. B.S. Revzin, Axial compressors of gas turbine gas compressor units (Textbook, Yekaterinburg, USTU-UPI, 2007).

3. S.V. Tsanev, V.D. Burov, A.S. Zemtsov, A.S. Osyka, edited by S.V. Tsaneva, Gas turbine power plants, manual for universities (MPEI, Moscow, 2011).

4. A.D. Legkiy, V.N. Zlobin, A.M. Sorokin, International Journal of Applied and Basic Research 12, 189-194 (2018).

5. L.R. Kouchtch, Catalytic coatings to optimize the burners of Heat Systems, Proceedings of the international scientific conference on the 40th anniversary of KSPEU "Energy - 2008: innovations, solutions and perspectives", Kazan, 2008.

6. V.N. Zlobin [et al.], Installation for coating, Patent Rus. Federation, 27, 98003. IPC: C23C 14/46 / № 2010113619/02 (019,203), 2010.

7. Y.A. Cherkasov [et al.], A method of manufacturing a catalytic converter element exhaust gases of internal combustion engine: US Pat. Ukraine 43128 A: July 7 F02B51 / 02 / - № 2000127122, 6 (2001).

8. M.G. Bannikov [and others.], Using ion implantation technology for catalytic coatings on different surface, Advanced Materials-2001: proceedings of the 7th international Symposiym on Advanced Materials, Islamabad, Pakistan, 2001.

9. V.N. Zlobin, I.P. Vasiliev, Ion implantation energy and mechanical engineering (Volgograd State Technical University, Volgograd, 2018).

10. S. Laubenstein, Katalytische Abgasreinigungfür Stationer-Motoren (Info- Broschüre, H.U.T. Heuwieser Umwelttechnik GmbH, 1998). 
11. W. Maus, R. Brück, Zukunft der heterogenen Katalyseim Automobil, «Turbolente» Katalysatorenfür Otto- und Dieselanwendungen, 26. Internationales Wiener Motoren symposium, 2005.

12. O. Klus, I. Vasilev, Preliminary thermal \& catalytic fuel treatment in a diesel engine injector, $25^{\text {th }}$ CIMAC World Congress on Combustion Engine Technology, Preliminary programme, Vienna Austria, 20017, 2017.

13. I. P. Vasiliev, Regulated introduction of catalyst atoms by ion implantation method, High, critical electro-and nanotechnologies: proceedings of the Scientific and Technical Conference on June, Tula, TulSU 7, 99-106 (2017).

14. O. Klyus, I. Wasiliew, ZeszytyNaukowe. Akademia Morska w Szczecine, Szczein 27 (99), $215-23$ (2011). 